\title{
Summertime modification of surface fronts in the North Atlantic subpolar gyre
}

\author{
Agnès Desprès, ${ }^{1}$ Gilles Reverdin, ${ }^{1}$ and Francesco d'Ovidio ${ }^{1}$ \\ Received 7 January 2011; revised 14 June 2011; accepted 7 July 2011; published 4 October 2011.
}

[1] A 12-yearlong thermosalinograph data set from ships of opportunity was used to make an extensive study of meso-scale surface fronts in the western part of the North Atlantic subpolar gyre from 1997 to 2009. Fronts are identified on a sea-surface-salinity/sea surface temperature gradient criterion with a typical width of 20 to $60 \mathrm{~km}$. The seasonal hydrographic properties of fronts are investigated. We find that, whereas salinity jumps across fronts are close to the larger scale variations, the temperature jumps across fronts are often smaller than the larger scale variations, in particular in summer-time.

We also find in June vertical profiles that the relative weight of temperature over salinity in the density jump across fronts is smaller at the surface than at depth. A Lagrangian model based on altimetry data and in situ vertical hydrographic profiles indicates that surface stirring is able to create fronts, but not the contrast between temperature and salinity gradients. We suggest that air-sea fluxes, mostly heat fluxes, but possibly also differential vertical stirring, are responsible for damping the meso-scale horizontal surface temperature gradient. This is supported by an eddy-permitting numerical simulation of this region (DRAKKAR simulation ORCA-025-G70) which includes some heat flux feedbacks.

Citation: Desprès, A., G. Reverdin, and F. d'Ovidio (2011), Summertime modification of surface fronts in the North Atlantic subpolar gyre, J. Geophys. Res., 116, C10003, doi:10.1029/2011JC006950.

\section{Introduction}

[2] In all seasons, between $55^{\circ}$ and $64^{\circ} \mathrm{N}$, the sea surface temperature (SST) and salinity (SSS) fields indicate positive salinity and temperature gradients between the central Irminger Sea (Figure 1b) and the Reykjanes Ridge, which bounds to the east the Irminger Sea [Bersch, 2002; Hatun et al., 2005; Boyer et al., 2006]. This contrast originates from the circulation [Fratantoni, 2001; Reverdin et al., 2003; Flatau et al., 2003] bringing fresh and cold surface waters from the Labrador Sea or off the east Greenland Current to the central part of the Irminger Sea, and branches of the North Atlantic Current bringing warmer and saltier water across the Reykjanes Ridge (Pollard et al., 2004). Because of bathymetry, this circulation is strongly modulated by the Reykjanes Ridge, with the Irminger Current flowing northward on the western side of the Reykjanes Ridge and channeling these warmer and saltier waters from the Iceland Sea (Figure 1a).

[3] In a previous paper [Desprès et al., 2011, hereinafter DRD], we studied how stirring structures the thermohaline gradients at meso and smaller scales. The analysis in DRD identified fronts from salinity gradients, and attempted to reconstruct them with a Lagrangian method, based on the advection of seasonal climatological fields with the current field from altimetric products. In DRD we found that the

\footnotetext{
${ }^{1}$ LOCEAN, Institut Pierre-Simon Laplace, Université Pierre et Marie Curie, Paris, France.

Copyright 2011 by the American Geophysical Union. 0148-0227/11/2011JC006950
}

main regional patterns in the presence of (sub-)meso-scale salinity fronts observed from in situ data can be reconstructed by stirring a large-scale climatological salinity field with altimetry-based velocities. In most of the region, this result pointed to the primary role of horizontal stirring in driving frontogenesis, and on the possibility of predicting front location by merging Lagrangian tools, altimetry data and climatological surface salinity.

[4] However, in some cases, an important mismatch was noted between reconstructed and observed salinity fronts. This is the case for the seasonal appearance of fronts near $59.5^{\circ} \mathrm{N} / 40^{\circ} \mathrm{W}$ (site A of DRD) or close to the west of the Reykjanes Ridge all year-round, areas which are not characterized by large eddy variability. Furthermore, similar results are found when reconstructing the front distribution with the passive stirring of a large-scale gradient for temperature instead of salinity, but with a larger mismatch in the summer season, when too many fronts are simulated. Observations during summer also tend to present more differences between temperature and salinity fronts, with more than half of the fronts detected with one variable and not the other.

[5] The approach adopted by DRD assumed advection of a passive tracer, thus no heat/freshwater forcing for temperature/ salinity. However, the presence of oceanic fronts or eddies at midlatitudes, even weak ones, is known to strongly influence local air-sea fluxes (heat, evaporation and wind stress) [e.g., Friehe et al., 1991; Bourras et al., 2004; Xie, 2004; Chelton et al., 2004] (see review by Small et al. [2008]). This in return could modulate upper ocean thermohaline properties 
a)

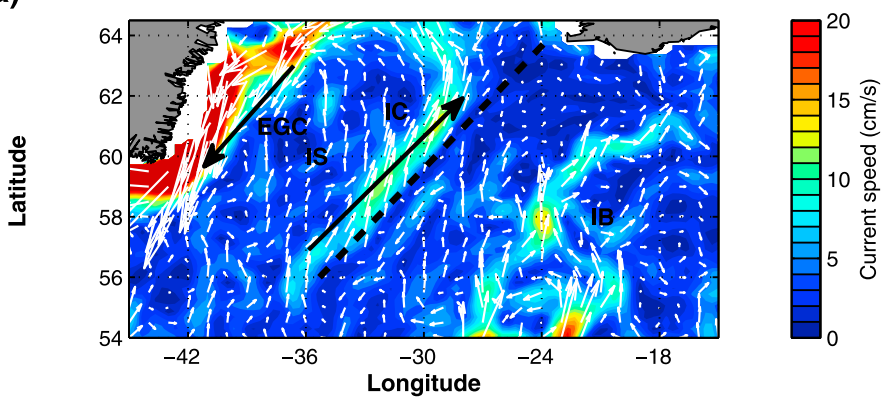

b)
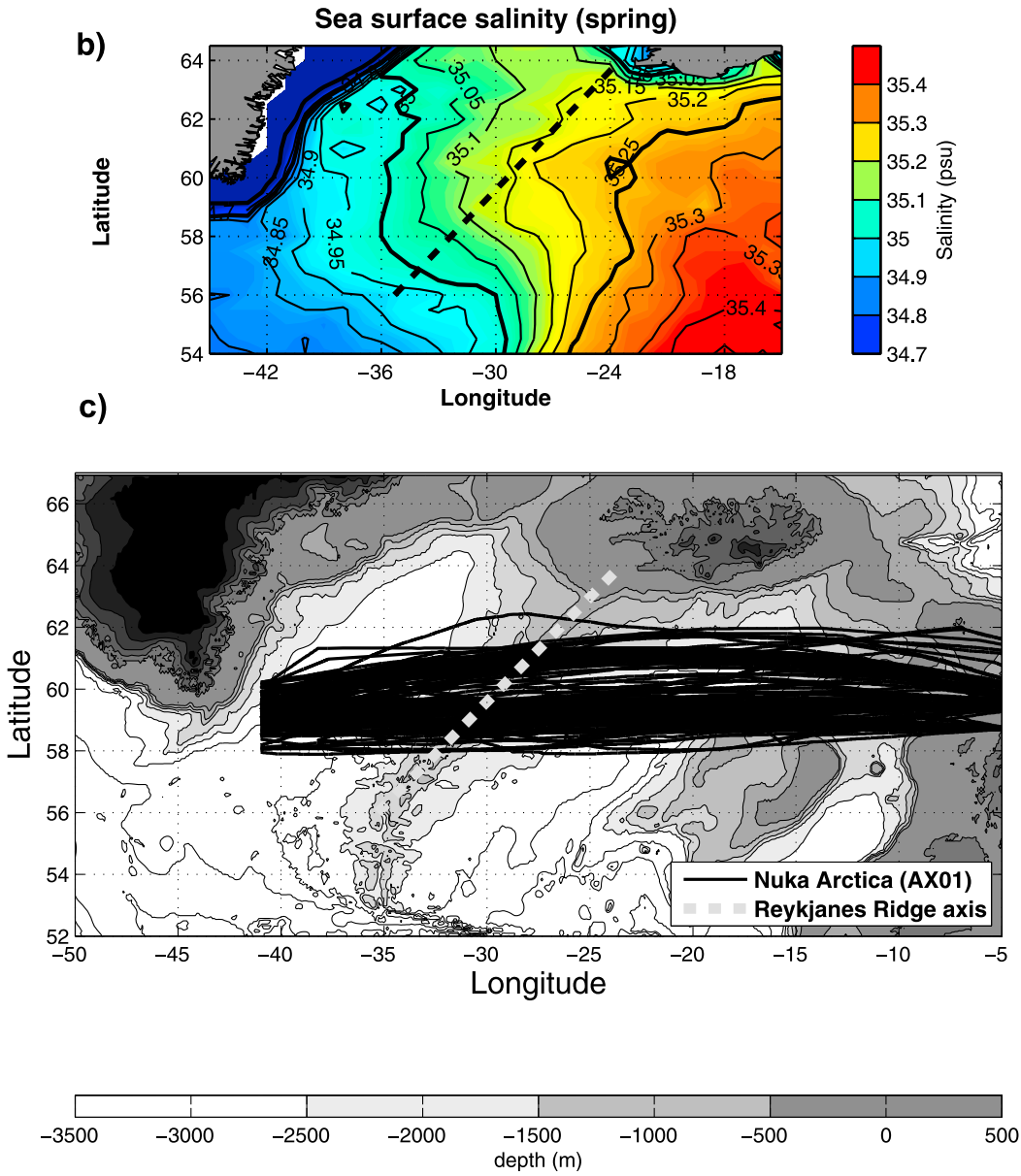

Figure 1. (a) Surface circulation in the subpolar gyre from altimetry in spring (AMJ): IS stands for Irminger Sea, IB for Iceland Basin, IC for Irminger Current, EGC for East Greenland Current; (b) climatological sea surface salinity in the subpolar gyre in spring (AMJ) and (c) position of the 1997-2009 sections used, superposed on ocean bathymetry. The average position of the top of the Reykjanes Ridge is outlined by a thick dashed line (white line on Figure 1c).

(damping gradients in temperature and increasing gradients in salinity), as well as influence mixed layer depth by preferential vertical mixing on the warm water side. In particular, modifications of SST gradients by local air-sea interaction across fronts are expected, when vertical temperature stratification is high and wind speed is variable in late spring and summer [ $\mathrm{Liu}$ et al., 1979].

[6] In this paper, we will characterize the thermohaline properties of surface fronts in the Irminger Sea, and investigate why the cross-frontal temperature gradients appear to be reduced in summer compared to the salinity gradients. This focus stems from the availability of numerous ships-ofopportunity thermosalinograph data in 1997-2009 (DRD) (Figure 1c), and of a set of three well-documented cruises [Lherminier et al., 2007]. Lagrangian calculations with realistic meso-scale currents will be used to statistically investigate the contribution of horizontal stirring to the temperature and salinity gradients near fronts. These serve as a background against which the observed temperature and salinity gradients can be evaluated. Eddy-permitting ocean simulations will also be used to investigate some effects of the atmospheric forcing on thermohaline properties of surface fronts. 


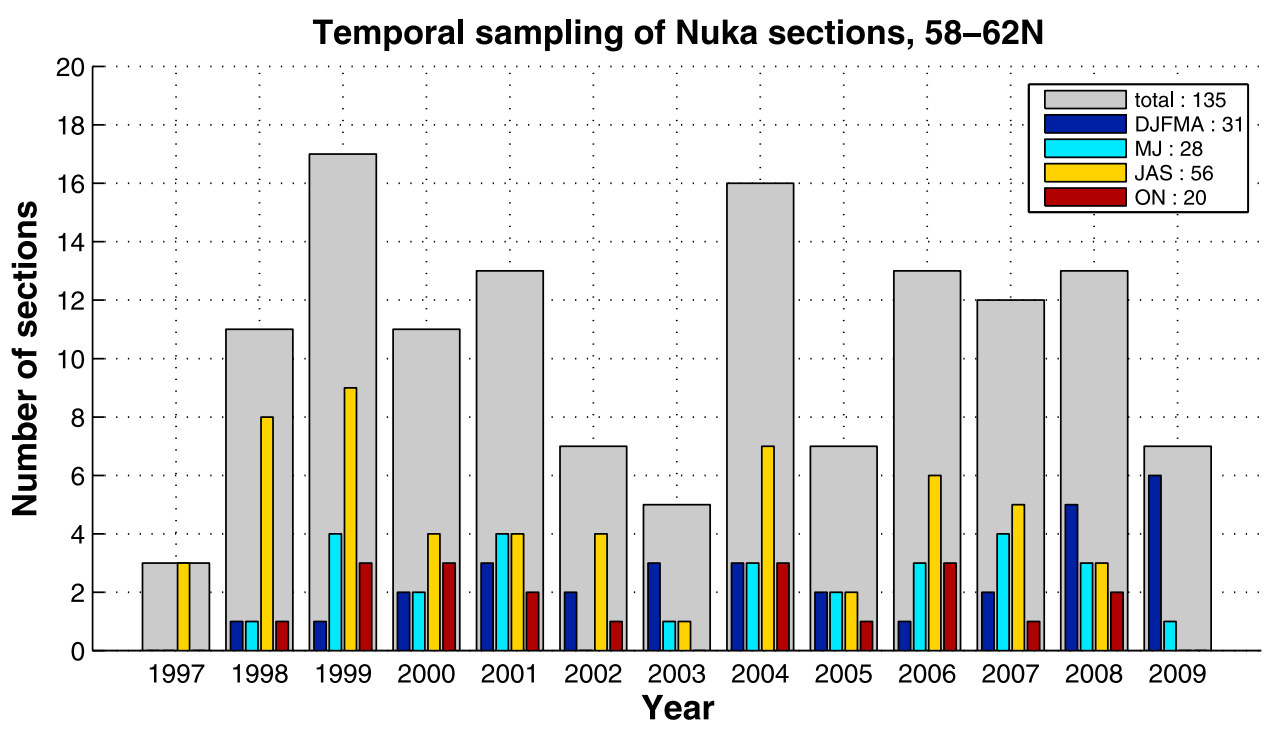

Figure 2. Temporal distribution of the TSG sections of the Nuka Arctica until May 2009, both by years (gray bars) and by season (color bars; DJFMA sections are reported for the January year).

[7] In section 2, we will present the in situ data, as well as how we estimate a front. We will then present the Ovide cruise data and the numerical simulations, as well as the analysis methods. In section 3, we discuss the seasonal variability of horizontal frontal properties. In section 4, we discuss vertical processes, and in particular stratification near the surface. Section 5 includes a comparison with model simulations and section 6 provides summary and perspectives.

\section{Data and Methods}

\subsection{Surface Hydrographic Data}

[8] One-minute averaged temperature and salinity data collected near 4-5 $\mathrm{m}$ depth by the container vessel Nuka Arctica (NA) were reported since July 1997 along line AX01 between the north of Scotland and Greenland. The ship often transects the Reykjanes Ridge between $58^{\circ} \mathrm{N}$ and $62^{\circ} \mathrm{N}$, and the data were averaged and reported on a $10-\mathrm{km}$ grid after thorough cleaning to eliminate erroneous data, the intermittent influence of bubbles, and corrected from possible biases in temperature and salinity. Further details on the data and the correction/reduction method are reported in DRD; the 10-km averaging was required to fill the gaps due to removed data. It results in 135 usable transects between $58^{\circ} \mathrm{N}$ and $62^{\circ} \mathrm{N}$ and July 1997 and June 2009 (DRD), while still resolving most meso-scale structures in the SST/SSS section. There may be a meteorological bias in the data, as the quality of the data was often low when facing very strong winds, resulting in data removal.

[9] Figure 1c depicts the position of all along-track data used from 1997 to 2009. The top of Reykjanes Ridge is sketched as a straight line north of $56^{\circ} \mathrm{N}$ (gray dashed line). The ship route (thin solid gray line) is often approximately zonal. In our study, we will especially focus on the sections crossing the Reykjanes Ridge between $58^{\circ}$ and $62^{\circ} \mathrm{N}$. A modified spatial coordinate system was used in some figures by projecting data along a zonal section at $60^{\circ} \mathrm{N}$, as a function of zonal distance from the top of the Reykjanes Ridge.
[10] In DRD, the data were used irrespectively of the season with an emphasis on salinity data. Here, we consider both temperature and salinity, and we seek to investigate the seasonal variability. Surface density was computed from the $10-\mathrm{km}$ reduced temperature and salinity. The temporal distribution of the data is very unequal between successive years (adequate from 1998 to 2001 and in 2004, 20062009), and between seasons during the whole sampling period (1997 to 2007), as shown on Figure 2. The winter NA data are only available since 2002 and are dominated by 2007-2009 data, while there is no usable transect in fall 2003. The best sampled months are in summer, but with a different number of sections for each year. To define seasons for Figure 2, we had to decide how to group the months in seasons. Based on seasonal cycle of SSS and SST, we adopt grouping in DJFMA (winter), MJ (spring), JAS (summer), ON (autumn). Alternatively, we could have based it on the seasonality of the heat and freshwater fluxes, as well as of the winds (thus vertical stratification), which would favor a winter DJFM, AM (spring), JJA (summer), and SON (autumn). The choice of seasonal grouping has largest impact on spring and autumn season statistics, but less so on summer which will be the core of the investigation.

[11] We define fronts as regions of strong local gradient by comparison to the larger scale gradient. For surface salinity, this is carried as in DRD according to a threshold gradient that holds over a minimal width. The value of SSS contrast across the Irminger Current (between 0.30 and 0.35 psu across $150 \mathrm{~km}$ ) reported in earlier papers [Holliday et al., 2006]; Pollard et al. [2004] made us choose a threshold gradient of 0.11 psu per $50 \mathrm{~km}$, thus 3 to 8 times larger than the seasonal large-scale salinity gradients. Because of the spatial scales investigated and the spatial smoothing/filtering applied on the data, we retain fronts only if the threshold is exceeded for at least $30 \mathrm{~km}$. This choice clearly prevents us from identifying filaments or features with scales close to the first baroclinic Rossby radius of deformation, which is near $10 \mathrm{~km}$ in this part of the subpolar gyre [Emery et al., 1984; Chelton 

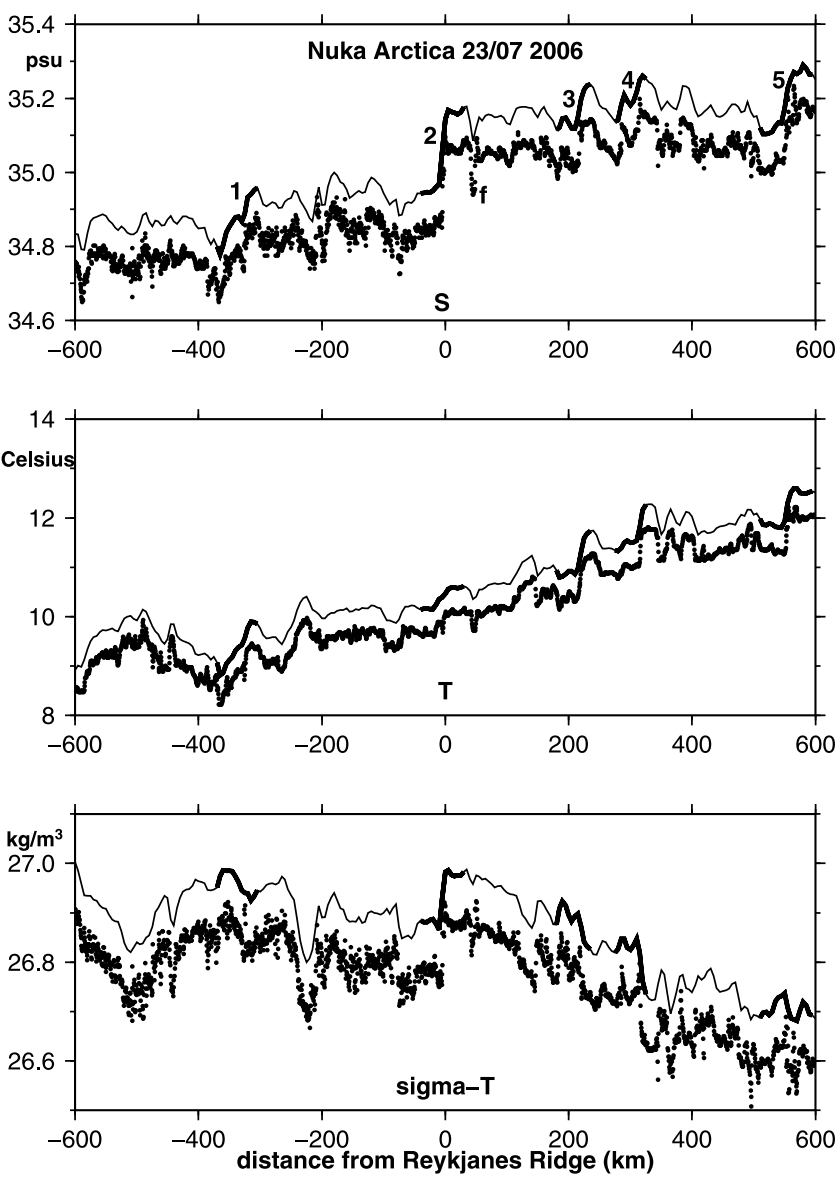

Figure 3. Example of the original 1-km (dots shifted down) and reduced 10-km (lines) T, S and density anomaly (density-1000 $\mathrm{kg} \mathrm{m}^{-3}$ ) data from a TSG section on 22-23/ 07 2006. The section is reported as a function of zonal distance to the Reykjanes Ridge top crossed at $59.2^{\circ} \mathrm{N}$ (negative values in the Irminger Sea, positive values in the Iceland Basin). Fronts identified both in $\mathrm{T}$ and $\mathrm{S}$ are indicated with a thicker line (numbered 1 to 5), and a smaller scale filament is identified by " $\mathrm{f}$," $50 \mathrm{~km}$ east of the Reykjanes Ridge.

et al., 1998] (cf. feature $\mathrm{f}$ on Figure 3, $40 \mathrm{~km}$ east of the Reykjanes Ridge).

[12] For surface temperature, we decided to adopt similar criteria, but with a threshold weighted with respect to the salinity threshold, so that the respective contributions of those threshold $\mathrm{T}$ and $\mathrm{S}$ gradients to the density gradient have the same ratio (density ratio) as the one for larger scales $\mathrm{T}$ and $\mathrm{S}$ gradients for the particular section (for most of the fronts considered here which are in the central or eastern Irminger Sea, this large scale ratio is estimated between $-500 \mathrm{~km}$ and $100 \mathrm{~km}$ from the top of the Reykjanes Ridge after applying a $200-\mathrm{km}$ smoothing to the $\mathrm{T}$ and $\mathrm{S}$ data). In this study, each identified front is characterized by its gradients in SSS $(\mathrm{psu} / 50 \mathrm{~km})$, SST $\left({ }^{\circ} \mathrm{C} / 50 \mathrm{~km}\right)$ and density $\left(\mathrm{kg} \cdot \mathrm{m}^{-3} / 50 \mathrm{~km}\right)$, its location, time, width, and density ratio «DR» defined as the ratio of the contributions of temperature and salinity on density (with the opposite sign)

$$
\mathrm{DR}=\alpha^{*} \Delta \mathrm{T} / \beta^{*} \Delta \mathrm{S}
$$

( $\alpha$ and $\beta$ been the local thermal and saline expansion coefficients).

[13] Compensated (no density gradient) fronts have a density ratio of 1 , whereas temperature-dominated fronts have a ratio larger than 1 and salinity-dominated fronts have a ratio less than 1.

[14] We are seeking possible differences in the respective contributions of $\mathrm{T}$ and $\mathrm{S}$ to horizontal density gradients at the frontal scale relative to what is found at the larger scale, thus considering joint $\mathrm{T}$ and $\mathrm{S}$ fronts with the criteria adopted to identify fronts may statistically dampen the difference to the larger scale, but will not influence the average sign of this difference. The large-scale density gradient presents section to section variations near the Reykjanes Ridge, with a climatological seasonal cycle emphasizing a weaker density ratio from July to October just west of the Reykjanes Ridge.

[15] Figure 3 shows the cleaned 1-min averaged and 10-km gridded S (first panel), T (second panel) and density (third panel) for a zonal section in July 2006. Five joint SSS/SST fronts are identified on this particular section. Interestingly, the strongest SSS front, located near the top of the Reykjanes Ridge (near $59.4^{\circ} \mathrm{N}$ ), has a rather small SST signature. In that case, the associated density section is temperature dominated on the large scales and for some of the fronts, but is clearly salinity dominated (increasing density to the east) for the Reykjanes Ridge front.

[16] In Figure 3, the fronts in $\mathrm{T}$ and $\mathrm{S}$ mostly co-locate. However, in the 12-year data set, there are a large number of fronts in one of the two variables that are not identified in the other variable. For example, in winter, 48 fronts are found in $\mathrm{T}$ and $\mathrm{S}$, whereas 36 fronts are found only in $\mathrm{S}$ and 65 only in T. However, in summer, the proportion of fronts only found in one of the two increases considerably, with 92 fronts identified in the two variables, while 168 are identified only in S and 213 only in T. Fronts identified both in $\mathrm{T}$ and $\mathrm{S}$ are more likely to have a dynamical origin as in DRD. Qualitatively, the results of this paper are similar when retaining all the fronts found in $\mathrm{S}$ or $\mathrm{T}$, but this would also include fronts that result primarily from spatial variations in short-term atmospheric forcing (either heat fluxes of freshwater fluxes).

\subsection{Ovide Cruises}

[17] We used data from three Ovide cruises from Portugal to Greenland that took place in June 2002, 2004 and 2006 on the R/V Thalassa. During these cruises, $\mathrm{T}$ and $\mathrm{S}$ from a thermosalinograph and currents from a hull-mounted acoustic Doppler current profiler were collected along the track nearly every $1 \mathrm{~km}$. T, S and current full profiles were obtained from CTD/acoustic current profiler casts roughly every $40 \mathrm{~km}$ in the Irminger Basin [Lherminier et al., 2007]. The resulting sections cross the top of the Reykjanes Ridge near $58.7^{\circ} \mathrm{N}$ and the Greenland shelf edge just south of $60^{\circ} \mathrm{N}$. They are thus crossing the same region as the Nuka Arctica and are likely to intersect a large part of the surface hydrographic fronts in this region at right angles (DRD).

\subsection{Ocean Circulation Model}

[18] The idea is to investigate meso-scale ocean simulations to find what influences the surface properties of ocean fronts associated with meso-scale structures. 

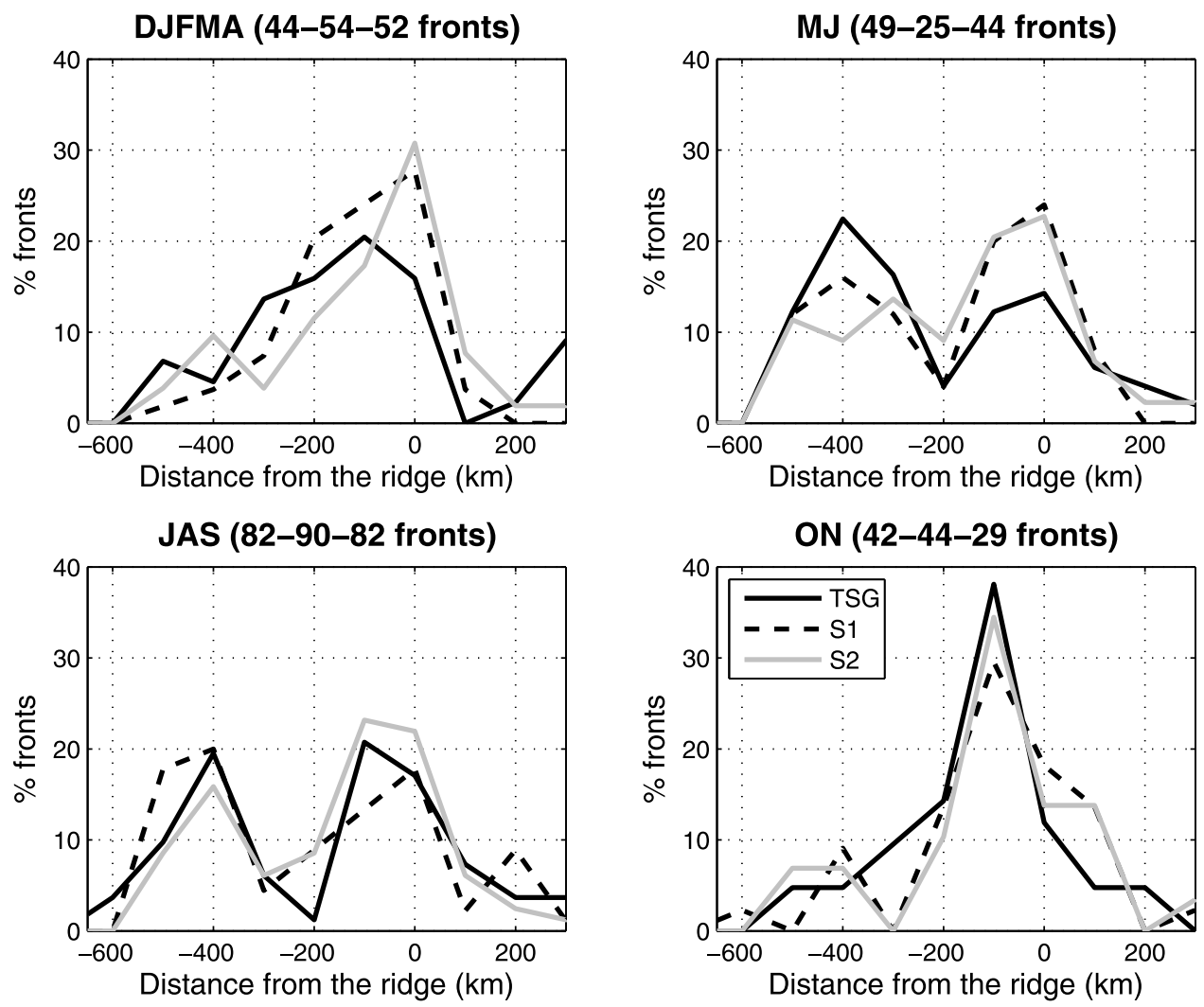

Figure 4. Distribution of the surface fronts along the Nuka Arctica sections as a function of zonal distance to the Reykjanes Ridge top for the 4 seasons. The figures are presented as normalized percentage of fronts in 100-km bins for TSG (dark solid line) and for altimetry-driven Lagrangian simulations S1 (dark dashed line) and S2 (light solid line). The total number of fronts observed (TSG), and in S1 and S2 are indicated in each label.

[19] In order to achieve this, we use long experiments (1958 to 2004) with $1 / 4^{\circ}$ model configuration ORCA025G70 performed by the DRAKKAR project [Molines et al., 2006]. This configuration is based on the version 1.12 of NEMO, on an «ORCA» type grid with a horizontal resolution of $1 / 4^{\circ}$ in longitude at the equator (roughly $10 \mathrm{~km}$ in this part of the North Atlantic subpolar gyre) and 46 vertical levels [Lique et al., 2009]. The atmospheric forcing is largely based on ECMWF (European Center for Medium rage forecasts) analysis between 2002 and 2004, and on ERA40 (European reanalysis of ECMWF) before 2002. ERA40/ECMWF SST presents no ocean meso-scale variability in this region and thus this atmospheric analysis is devoid of atmospheric response to ocean meso-scales [Gulev et al., 2007]. On the other hand, the heat forcing formulation in ORCA025-G70 is expected to exert a negative feedback to ocean surface temperature meso-scales. See for example the discussion of such effects on ocean meso-scales in an eddy-resolving model by Shuckburgh et al. [2011]. The model also presents a weak relaxation toward a large-scale salinity climatology. This will also act as a negative feedback on the ocean salinity meso-scales.

[20] We use simulation outputs available every five days from January 1992 to December 2004, during part of the period we investigate. The simulation is eddy-permitting. It presents over the Irminger Sea a circulation that shares similarities with the observed one with a cyclonic cell and horizontal $\mathrm{T}$ and $\mathrm{S}$ gradients that are also of the right sign west of the Reykjanes Ridge. The circulation has eddy variability west of the Irminger current, as well as a secondary peak close to $400 \mathrm{~km}$ to the west of the ridge in the central Irminger Sea that have correct magnitudes. Fronts are identified in the simulation in a similar way as for the observations. The simulated fronts tend to be wider than the observed ones, as is expected from the limited model grid resolution. The simulation presents fronts both west of the Irminger Current and in the central Irminger Sea, albeit with a different spatial or seasonal distribution than observed.

\subsection{Lagrangian Model}

[21] In order to single out the role of horizontal stirring in the distribution of fronts, we use a Lagrangian model in which surface salinity and temperature climatological fields are passively advected by altimetry-derived meso-scale velocities [Lehahn et al., 2007; d'Ovidio et al., 2009]. The model constructs particle trajectories with a $6 \mathrm{~h}$ step, fourth order Runge-Kutta integrator fed by current fields from Archiving, Validation, and Interpretation of Satellite Oceanography Data (AVISO) altimetry data (see DRD for details).

[22] The tracer fields advected by the model are a SSS monthly climatology (used by Reverdin et al. [2002]) and a SST monthly climatology [Reynolds and Smith, 1994]. In order to develop filaments, the cascade of chaotic stirring needs advection timescales corresponding to the inverse of 

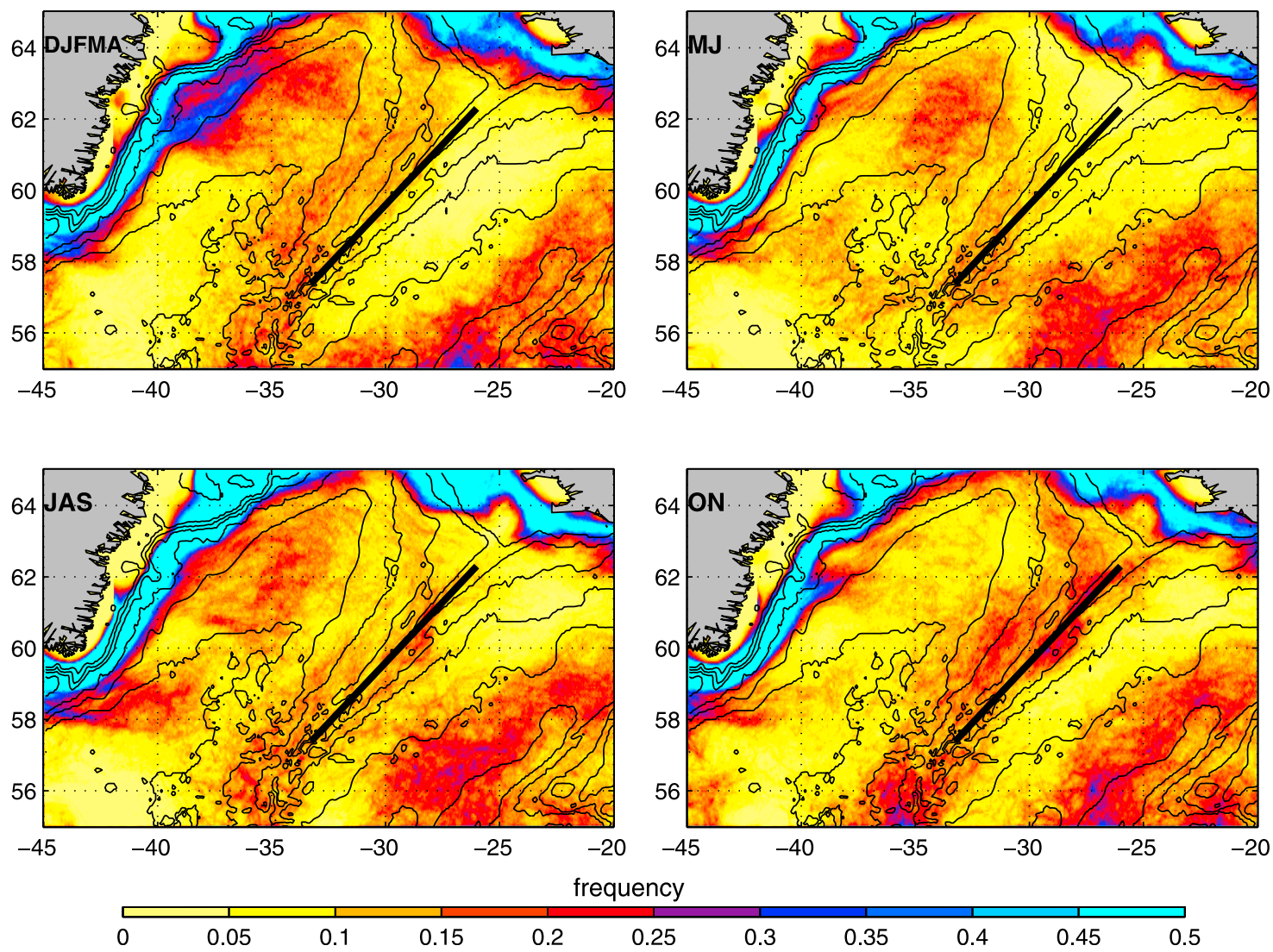

Figure 5. Frequency of presence of fronts (in any direction) for the four seasons in the Lagrangian simulation S1. Bathymetry is reported every $500 \mathrm{~m}$ as thin lines, and the position of the top of the Reykjanes Ridge is outlined as a thick line.

Lyapunov exponents (a few tens of days, in this region, DRD). As discussed in DRD, the best agreement in average SSS front statistics along the NA tracks is obtained for integration times of 30 days, which will also be adopted here. Altimetric meso-scale currents are the mapped $1 / 3^{\circ}$ resolution geostrophic currents computed from satellite sea surface height measurements and provided by AVISO every seven days [Le Traon et al., 2001; Rio and Hernandez, 2004].

[23] To discriminate the effect of large-scale $\mathrm{T}$ and $\mathrm{S}$ structures from the one of meso-scale currents on the seasonal distribution of fronts, we conducted two Lagrangian experiments with these weekly meso-scale currents required to develop filaments and meso-scale fronts, one with the seasonal climatological $\mathrm{S}$ and $\mathrm{T}$ fields (Lagrangian simulation S1), and one with the annually averaged climatology in $\mathrm{T}$ and $\mathrm{S}$ (Lagrangian simulation S2). Notice that none of these simulations are sensitive to ocean-atmosphere coupling, and thus frontal contrasts reflect the ones in the T,S fields used, either local or non-local.

\section{Seasonal Variability of Frontal Properties}

\subsection{Location of Fronts}

[24] There is a noticeable seasonal contrast in front identification: the average number of fronts identified both in $\mathrm{T}$ and $\mathrm{S}$ per section is 1.6 in winter and 0.8 in spring respectively, but increases to 1.8 in summer and 2.4 in fall respectively. The location of positive (bold line) fronts from the Nuka Arctica presents a strong seasonal distribution as a function of distance from the Reykjanes Ridge (Figure 4). In particular, there is a peak present in spring and summer near $-400 \mathrm{~km}$, which is absent in the autumn and winter, whereas the peak close to $-100 \mathrm{~km}$ west of the ridge is very dominant in autumn. In winter, the distribution of fronts is very broad west of the Reykjanes Ridge and toward the central Irminger Sea (to $-300 \mathrm{~km}$ ). This seasonality is rather well captured in the Lagrangian simulation S1, albeit with a weaker $-400 \mathrm{~km}$ spring peak, and the eastern peak tend to be located close to the ridge top, a few tens of $\mathrm{km}$ to the east further than the observed one (except in the autumn). Lagrangian simulation S2 (which has no climatological S or $\mathrm{T}$ seasonal cycle) presents less seasonality, and a two-peak structure only in summer. This summer two-peak structure is probably a combination of eddy dynamics and the location of the summer crossings, whereas the seasonal occurrence of the $-400 \mathrm{~km}$ southern Irminger Sea fronts is largely dependent on the seasonality of $\mathrm{T}$ and $\mathrm{S}$ large-scale gradients (present in S1, but not in S2), possibly a non-local effect, as was argued in DRD.

[25] Part of the observed seasonality along the Nuka Arctica crossings is linked with seasonal changes of the ship track, which tend to be more commonly further north in the spring and summer seasons, whereas front positions present 

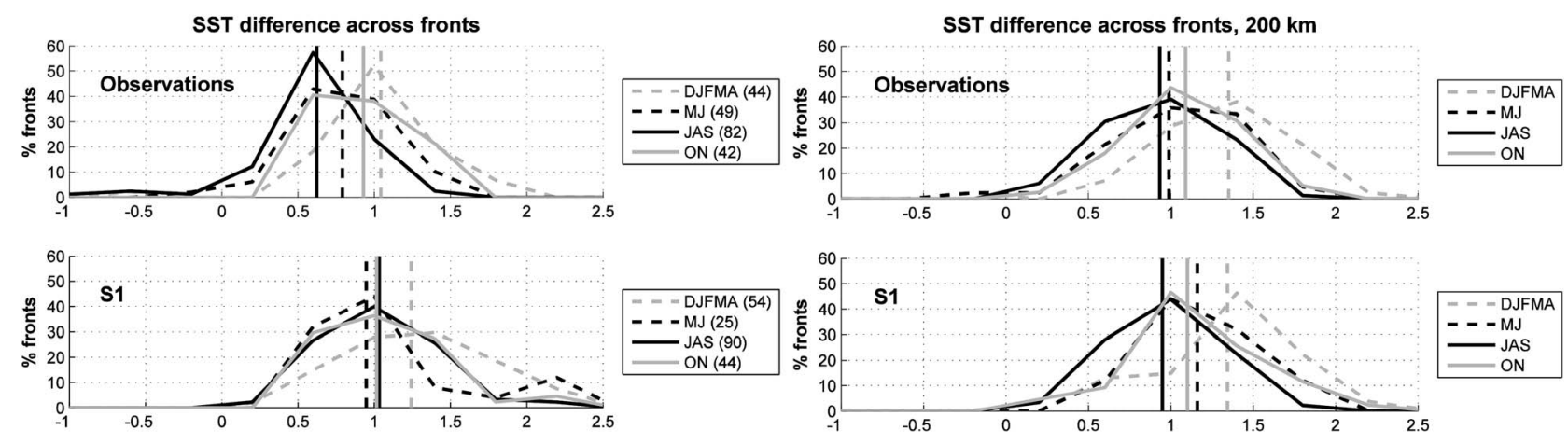

Figure 6. Normalized histograms of temperature differences (left) across the fronts and (right) over $200 \mathrm{~km}$ centered on the frontal position along the Nuka Arctica sections and for different seasons (different lines). (top) For the observed TSG data; (bottom) for Lagrangian simulation S1. The histograms are by class of $0.5^{\circ} \mathrm{C}$ and are normalized to sum up as $100 \%$. The median value is indicated for each distribution as a vertical bar, and the number of fronts is reported with the captions.

a large spatial variability (see DRD for salinity fronts). However, the Lagrangian simulation S1 also presents a large seasonal variability, as illustrated by the statistics of occurrence of Lagrangian simulation S1 fronts found both in $\mathrm{T}$ and $\mathrm{S}$ (Figure 5). This seasonal variability is not just located near the $-400 \mathrm{~km}$ peak, but also further north along the northern rim of the Irminger Sea or just west of the Reykjanes Ridge (maximum in autumn and winter). It is less present in Lagrangian simulation S2 which suggests a larger influence on front positions from the seasonal changes in the large-scale temperature and salinity fields, than from the seasonality of ocean circulation and eddy variability.

\subsection{Seasonality of T, $\mathbf{S}$ Across Fronts and Density Ratios}

[26] For some summer fronts, as for the one in Figure 3 located close to the top of the Reykjanes Ridge, the crossfrontal jump deviates widely from the large-scale difference. To quantify this feature statistically and seek its seasonal dependence, we need to define more precisely what we refer to as the large scale. This scale should not incorporate more than one frontal region in the average, and thus not be larger than $200 \mathrm{~km}$ according to Figure 4 . It should be larger than the scale of eddies, and thus the averaging is at least over $100 \mathrm{~km}$ (DRD). On the basis of these two requirements, we chose to estimate the large-scale jump by smoothing the data with a $200-\mathrm{km}$ running average and taking the difference between -100 and $100 \mathrm{~km}$ of the fronts.

[27] We will discuss and compare jumps at the frontal scale and at this large scale for different seasons and seek whether there are some systematic differences. To find what does not originate from frontogenesis induced by horizontal stirring, we will also discuss equivalent statistics based on Lagrangian simulation S1. At first order, for salinity (not shown) both in the observations and the Lagrangian simulation $\mathrm{S} 1$, there is a small seasonal dependency on the jumps with comparable magnitude at frontal scale and for the larger scale. In the observations there is a slight tendency for larger salinity jumps at the frontal scale compared to the larger scale. At the larger scale for temperature, there is a seasonal dependency with stronger jumps in winter, which is similar for the observations and the Lagrangian simulation S1 (Figure 6). In the Lagrangian simulation $\mathrm{S} 1$, the seasonal cycle of $\mathrm{T}$ is also similar at the frontal scale, whereas in the observations, the frontal jumps of $\mathrm{T}$ are often smaller than at the $200-\mathrm{km}$ scale.

[28] The difference in scale-dependence of observed variability for $\mathrm{T}$ and $\mathrm{S}$ implies large differences in the distribution of density ratio across fronts compared to the larger scale. Thus, in the observations, the median density ratio is smaller in summer at the frontal scale (0.93) than at the larger scale (1.37). In the other seasons, the difference between the median density ratio at these two scales for observations has the same sign, but is less in autumn (0.30) and in winter (0.21). Such differences are not found in the Lagrangian simulation $\mathrm{S} 1$.

[29] We illustrate these properties in a composite section obtained by combining the contributions of $\mathrm{T}$ (or $\mathrm{S}$ ) to density relative to each frontal individual centered position $(0$ on Figure 7$)$ and frontal center $\left(\mathrm{T}_{0}, \mathrm{~S}_{0}\right)$. Because identified fronts have different widths, we decided to stretch each front to a common $20 \mathrm{~km}$ width, so that the frontal edges are arbitrarily taken at $-10 \mathrm{~km}$ and $+10 \mathrm{~km}$ (distances further from the fronts are kept unstretched). We will compare these profiles obtained from the observations (Figure 7, left) and from Lagrangian simulation S1 (Figure 7, right). In the observations, the salinity profiles present a shape similar in all seasons with maximum deviations across the font, diminishing somewhat at larger distances (at least over $30 \mathrm{~km}$ on each side). The difference (and its contribution to density variations) is slightly larger during the summer season. In the observations, the shape of the average seasonal $\mathrm{T}$ profiles are also fairly similar in all seasons, but the minimum on the negative side of the front is not always located at $-10 \mathrm{~km}$ (more often near $-20 \mathrm{~km}$ ) and is not clearly identified during the summer season. The average contribution to density of the temperature jump across the front is thus smallest in summer (despite higher $\mathrm{T}$ and therefore $\alpha$ ) and larger in winter. This results in a contribution of $\mathrm{T}$ to the density jump across fronts that is slightly smaller (much larger) than the one of $\mathrm{S}$ in summer (in 
DJFMA

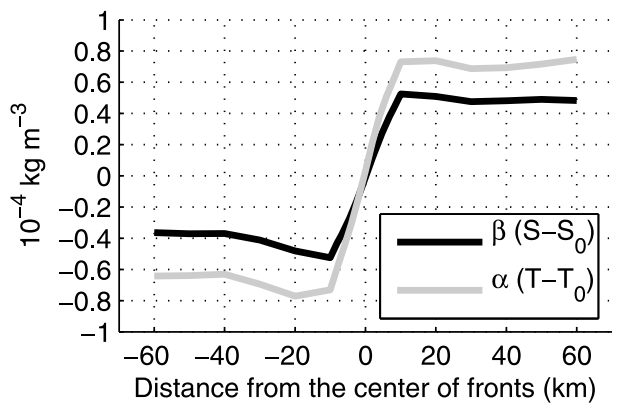

MJ

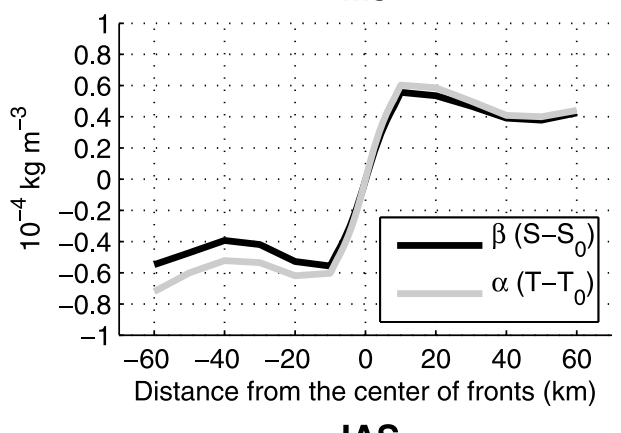

JAS

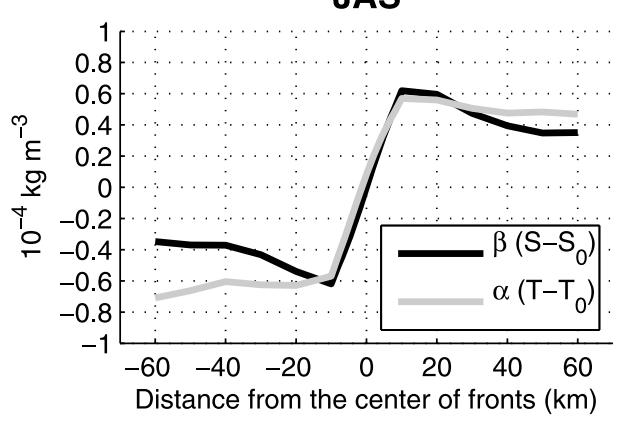

ON

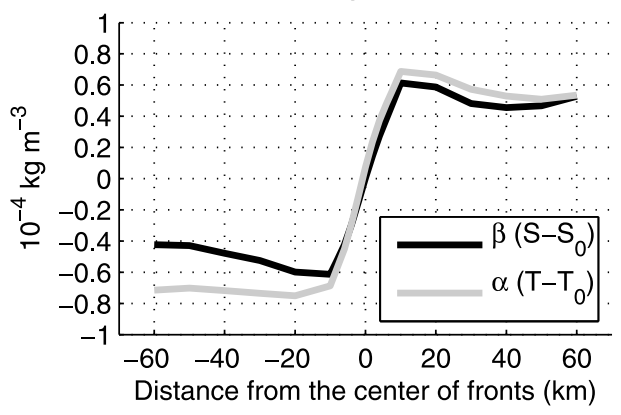

DJFMA

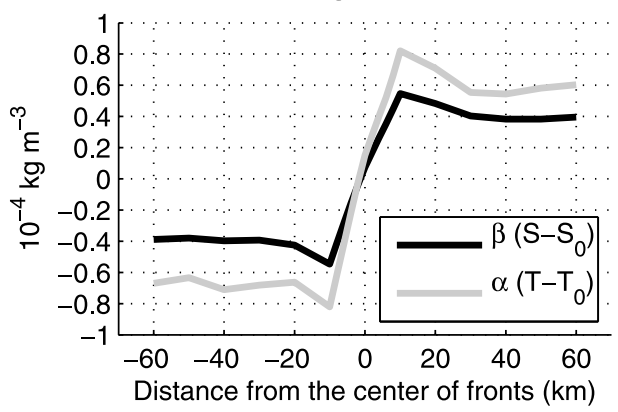

MJ

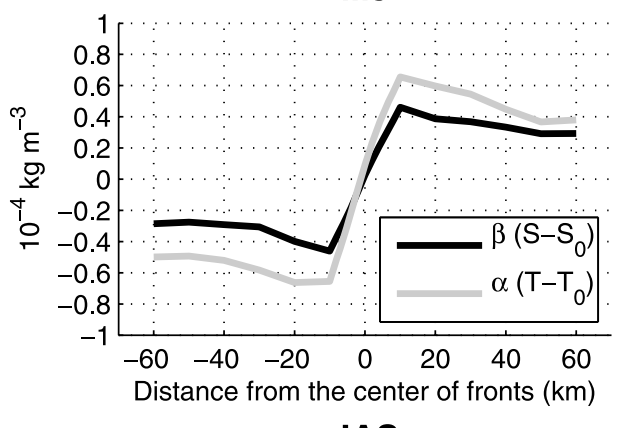

JAS

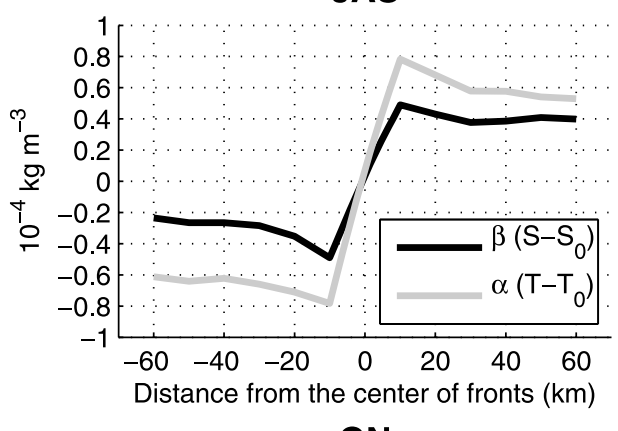

ON

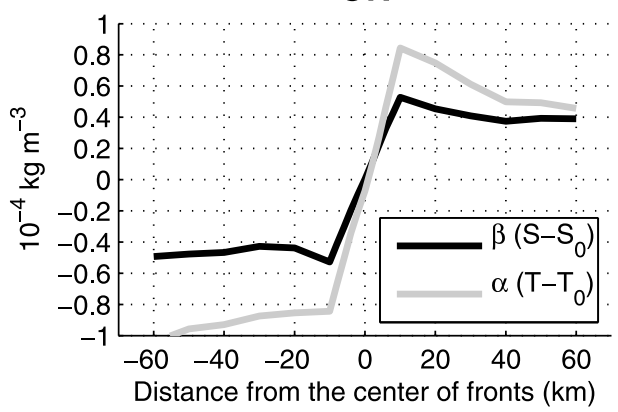

Figure 7. Averaged seasonal profiles of salinity-related (dark line) and temperature-related (light line) contributions to density across fronts, as a function of zonal distance to the frontal position (T0 and S0 are respectively the temperature and salinity at the front central position, and temperature contribution is plotted with the reverse sign). Frontal widths are all reduced to a common $20 \mathrm{~km}$ width, with real distances away from the front. (left) for observed TSG data; (right) for Lagrangian simulation S1.

winter). This difference between summer and winter is not observed at larger distances from the front.

[30] In contrast, in the Lagrangian simulation S1, the front width is similar for $\mathrm{T}$ and for $\mathrm{S}$ in all seasons. Furthermore, in summer and winter, the jumps and contributions to density differences in Lagrangian simulation S1 are similar at the frontal scale and at the larger scale, both for $\mathrm{S}$ and for $\mathrm{T}$. In the two other seasons (spring and autumn), there are small differences between the frontal scale and the large scale for $\mathrm{T}$ that show some similarities between observations and Lagrangian simulation S1, maybe an effect of the differences in spatial distribution of fronts between the different seasons. 

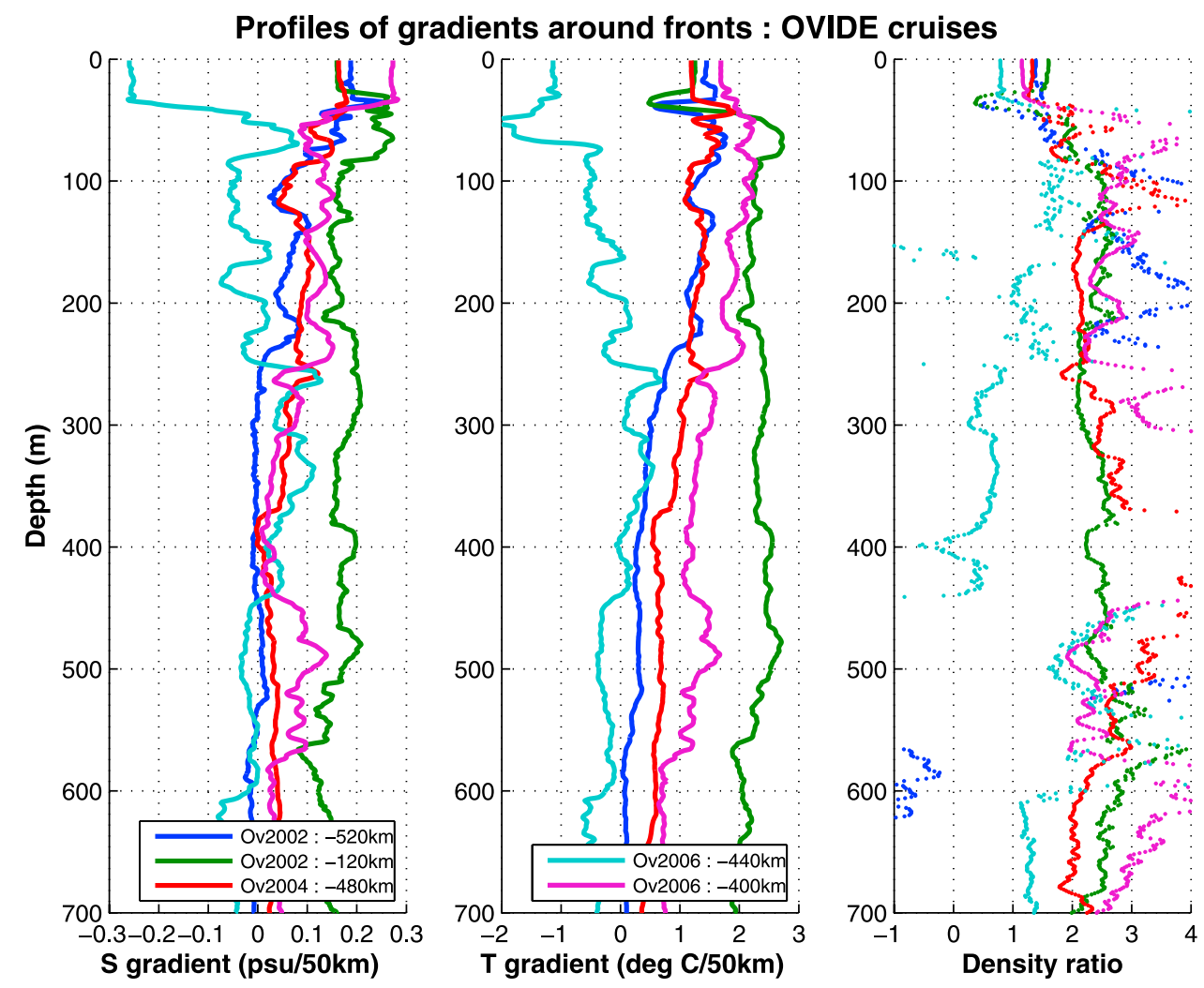

Figure 8. Individual vertical profiles of cross-front $\mathrm{S}, \mathrm{T}$ difference and corresponding horizontal density ratio (DR) for surface fronts identified in T and S during the 2002, 2004 and 2006 Ovide cruises in the Irminger Sea. The values are estimated from the closest pair of CTD profiles and normalized for $\mathrm{T}$ and $\mathrm{S}$ as a difference over $50 \mathrm{~km}$. The zonal distance to the Reykjanes Ridge top is reported in the caption for each front.

At the frontal scale, there is also a seasonal cycle in the density ratio that is larger in summer, as the simulated salinity jumps are smaller. Thus, there is a marked difference in the frontal scale characteristics between the simulation S1 and the observations, in particular in summer.

[31] This analysis thus suggests a scale-dependent process that modifies surface $T$ with respect to $S$ in the vicinity of fronts, and that is not due to passive horizontal advection.

\section{Comparison of Density Contrast Across Surface and Subsurface Fronts}

[32] Eleven surface salinity fronts are identified along the OVIDE sections $(2002,2004,2006)$ in late spring/early summer. Although all these fronts have a surface temperature signal associated with it, only five fronts are joint $\mathrm{T}$ and $\mathrm{S}$ fronts using the same criteria as for the Nuka Arctica sections (four are positive fronts and one is a negative front). These five fronts located in the western and central Irminger Basin have cross-section current extrema located within $20 \mathrm{~km}$ of the front position (not shown), suggesting formation of these surface fronts by eddy stirring as discussed in DRD for the Nuka Arctica surface fronts. The currents are surface or near-surface intensified with a subsurface baroclinic shear extending to at least $200 \mathrm{~m}$ in the central Irminger Sea and to $1000 \mathrm{~m}$ closer to the Reykjanes Ridge (not shown). The vertical profiles of salinity/temperature gradients (Figure 8) indicate that these surface fronts extend at subsurface, usually to similar depths as the currents (not shown). At subsurface, the fronts are temperature dominated and thus a positive $\mathrm{T}$ and $\mathrm{S}$ front (increase toward the east) is associated with a poleward surface current (as seen for Nuka Arctica fronts, cf. DRD).

[33] The density ratios across these fronts (from the pairs of successive CTD casts, separated by distances of 30 to $50 \mathrm{~km}$ ), indicate values less than 1.6 near the surface (Figure 8), and are smaller than the large scale surface density ratio for those sections (as seen in Nuka Arctica data). The surface density ratios are also smaller than the horizontal density ratio at subsurface, for example in the 100 to $150-\mathrm{m}$ depth layer. This layer is weakly stratified in $\mathrm{S}$, but stratified in $\mathrm{T}$, and is near the top of the layer that is a remnant of previous winter mixing in this region [Thierry et al., 2008]. The subsurface horizontal density ratio at the frontal scale is compatible with large scale horizontal density ratios at these depths, but also with the vertical density ratio, and thus could result either from horizontal stirring or from vertical isopycnal displacements related to the eddying meso-scale circulation. On the other hand, vertical advection of the subsurface water in the shallow weakly stratified surface layer (typically $30-\mathrm{m}$ deep) would contribute to a larger density ratio than observed (as would horizontal stirring, as discussed earlier in 3.2). Thus, the surface scale-dependent process resulting in the small 

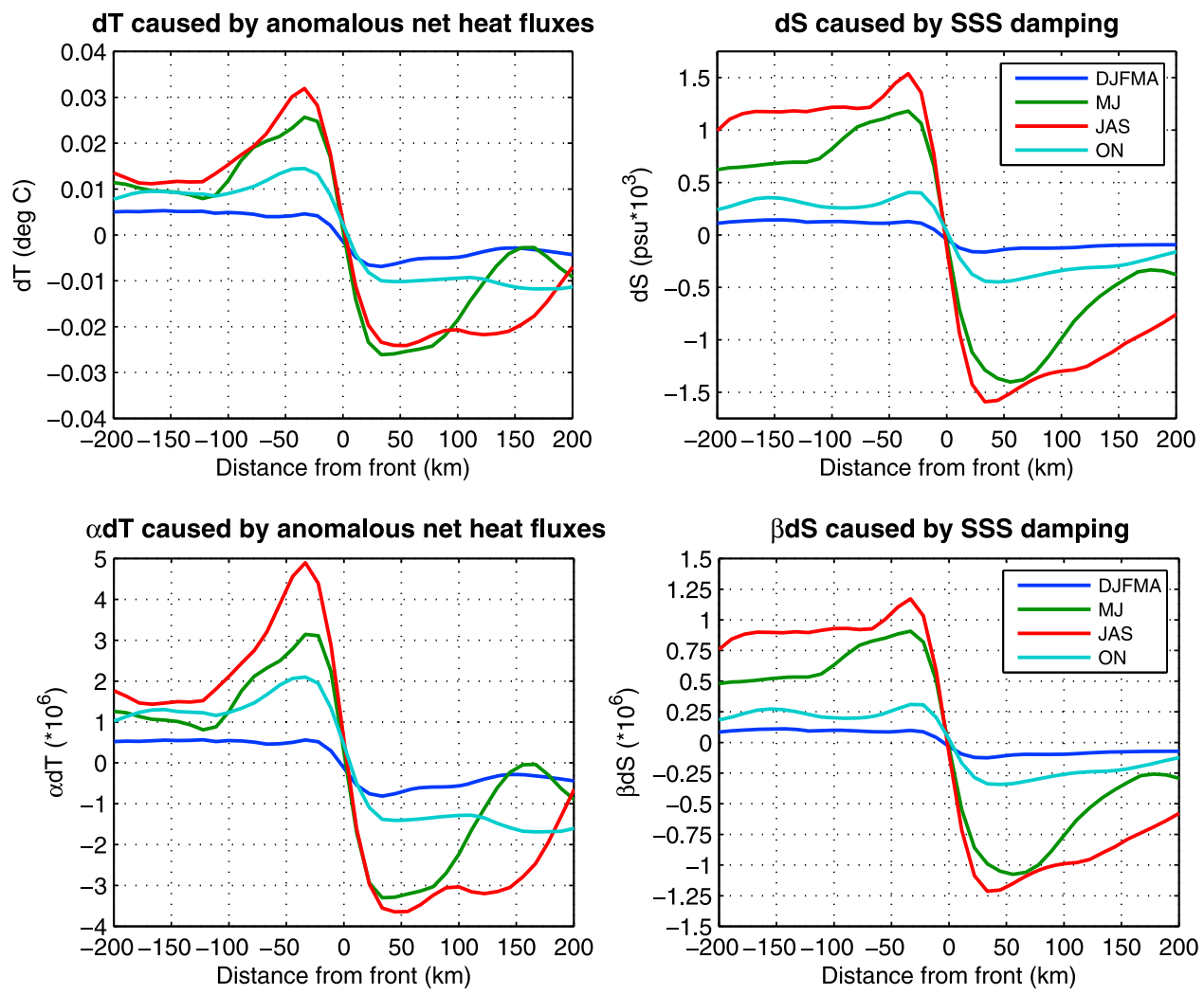

Figure 9. The 5-day changes in temperature and salinity contrasts across fronts in the ORCA-025 simulation west of the Reykjanes Ridge in the Irminger Basin, resulting for (left) T from the "anomalous" heat fluxes caused the temperature contrast and (right) $\mathrm{S}$ from the relaxation to climatology term (the values at the front center are removed before averaging). The lower panels present the respective contributions to density (with opposite sign for T; the panels for $\mathrm{T}$ and $\mathrm{S}$ contributions do not have the same vertical scale).

across-front density ratio is not just a mirror of the subsurface conditions.

[34] Furthermore, the other six portions of the sections with large $\mathrm{T}$ and $\mathrm{S}$ horizontal subsurface gradient, are associated with a surface $\mathrm{S}$ gradient of the same sign, but only 2 have a significant $\left(>0.3^{\circ} \mathrm{C}\right.$ over $\left.50 \mathrm{~km}\right)$ surface $\mathrm{T}$ gradient (the other fronts are thus salinity dominated at the surface with horizontal density ratios less than 1). This suggests as discussed before that processes which affect more $\mathrm{T}$ than $\mathrm{S}$ meso-scale surface gradients are taking place at the time of the Ovide sections in early summer.

\section{ORCA025 Simulation}

[35] The ORCA025 simulations present fronts in similar areas of the Irminger Sea as in the observations. We will review some characteristics of these fronts that are consistent to what is observed. The simulated temperature gradients across fronts are weaker in summer (and autumn) than in other seasons. Part of it is related to seasonality of large scale temperature gradients and of frontal positions, but we also find that the ratio of frontal gradients to large scale gradients in summer is smaller for $\mathrm{T}$ than for $\mathrm{S}$. At the $50-\mathrm{km}$ scale around surface fronts, the horizontal density ratio DR is also larger $(>2)$ below the mixed layer in the
100 to $200-\mathrm{m}$ layer compared to the surface in all seasons, and in particular during summer and autumn. A difference with the observations is that the largest difference between density ratio at the surface and at depth and the weakest surface density ratio across fronts occur during autumn (density ratio close to 1), and not during summer (1.2), possibly because the large scale surface density ratio are also the weakest in this simulation in autumn, whereas in the observations this occurred in summer.

[36] In the ORCA025 simulation, two processes contribute to the surface anomaly in density ratio and horizontal SST gradient at the frontal scale: air-sea fluxes (mostly heat) and differential vertical mixing across fronts. We will quantify the effect of the first one. Anomalies of the total air-sea fluxes as well as the mixed layer depth around positive fronts are estimated for each front along a crossfront section by first removing the average seasonal values for that date and location of the front. A smoothed largescale (over $200 \mathrm{~km}$ ) estimate of this anomaly is then removed and the composite of these residuals is constructed over all fronts. The composite for total heat flux presents a dipole anomaly pattern with positive anomalies on the cold side of the front, and negative anomaly of the warm side (not shown). The contrast reaches $15 \mathrm{~W} \mathrm{~m}^{-2}$ in winter and 
$8 \mathrm{~W} \mathrm{~m}^{-2}$ in summer. There is an associated small positive evaporative forcing feedback on $\mathrm{S}$ (increase of evaporation on the salty side). However, this is more than compensated by the negative feedback due to the relaxation on climatology of model salinity, which dominates in the salinity budget.

[37] The differential heat flux pattern would contribute to a systematic pattern on mixed layer depth being shallower on the cold side and deeper on the warm side of the front. This is present, with the exception of the autumn season (not shown). In summer, this anomaly is however small and less than $1 \mathrm{~m}$, compared to average values on the order of $30 \mathrm{~m}$. The differential mixed layer depth across the front has two effects on temperature contrast across the fronts. The first one is directly related to the depth over which the heat flux is distributed. During spring and early summer, when the total heat flux is positive for the ocean (warming), the heat flux distributed over a deeper layer on the warm side, contributes to less warming than on the cold side (with typical $50 \mathrm{~W} \mathrm{~m}^{-2}$ positive fluxes, this is however equivalent to less than $2 \mathrm{~W} \mathrm{~m}^{-2}$ anomaly in summer, thus much less than the heat flux feedback anomaly). The second effect is that this mixed layer deepening on the warm/salty side relative to the cold side due to differential heat flux is associated with more entrainment of subsurface water. As between spring and autumn, the ocean is stratified with deeper water being colder and saltier, this also contributes to lower the surface density ratio at frontal scale (we refer to it as the entrainment term).

[38] We can quantify the effect of air-sea fluxes on gradients across fronts and to the density ratio anomaly at frontal scale. The flux anomalies, both for heat and salt, are integrated over 5-day period over the model mixed layer depth (the time step of the model fluxes) (Figure 9). On the cold side of the front this produces a large warming maximum in summer exceeding $0.06^{\circ} \mathrm{C}$. There is also a damping of salinity gradients by the relaxation term to climatology, but with maxima of $1.5 \times 10^{-3} \mathrm{psu} / 5$ days, which is a fairly small term. The temperature heat flux negative feedback contributes to a reduction in the density gradient across the front, whereas the negative feedback on salinity contributes to an increase in density gradient, which is four times smaller. Thus these combined terms contribute to a net decrease in density ratio on the order of 0.15 in summer over 5 days. This effect is as large in May-June, but much less in the autumn (on the order of 0.05). For comparison, the entrainment term assuming an entrainment of a $1 \mathrm{~m}$-thick layer with $\mathrm{T}$ and $\mathrm{S}$ anomalies of $-1^{\circ} \mathrm{C}$ and $+0.1 \mathrm{psu}$ with respect to a summer surface layer of $30 \mathrm{~m}$, would contribute to a surface anomaly of $-0.03^{\circ} \mathrm{C}$ and $0.003 \mathrm{psu}$, and a decrease in density ratio (dominantly from the temperature) twice as small as the heat flux feedback in 5 days. As the fronts and eddies live longer than 5 days in this simulation and the estimates we provided for the entrainment term are upper estimates, the entrainment term is clearly a much smaller contributor than the differential heat flux pattern at frontal scales.

\section{Discussion}

[39] Nuka Arctica TSG sections across the Irminger Sea showed that salinity gradients were generally more influ- ential than temperature gradients in controlling the density structure of meso-scale fronts during summer months. Our approach focused on fronts identified both in $\mathrm{T}$ and $\mathrm{S}$, with a weighting of the $\mathrm{T}$ and $\mathrm{S}$ thresholds to identify fronts based on their respective large-scale gradients. Thus the summertime weakening in frontal-scale $\mathrm{T}$ jumps with respect to the large-scale gradients could have resulted in missing fronts detected for $\mathrm{S}$, but that would have a too weak $\mathrm{T}$-contrast to be identified as such. The differences between frontal-scale and large-scale jumps in $\mathrm{T}$ are not statistically significant in spring and autumn, albeit an average widening of the temperature fronts with respect to the salinity fronts is found in those seasons as well as in summer.

[40] The three Ovide sections (mostly in June) also illustrated a large difference between the characteristics of the five surface T-S fronts and the subsurface ones, in particular with less $\mathrm{T}$ horizontal gradients at the surface. Five out of the six surface S-only fronts present a clear subsurface signature, whereas all (12) subsurface T-S fronts were associated with surface $\mathrm{S}$ gradients of the same sign, with four of those presenting little surface $T$ gradients. The association of surface and subsurface $\mathrm{S}$ fronts supports the claim made in DRD that most early summer SSS fronts have a dynamical origin. In these sections, there is also an apparent reduction of the temperature gradients and density ratios at the frontal meso-scale. How does it originate?

[41] As reviewed by Small et al. [2008], potential candidates could be in the air-sea fluxes and their modulation in the presence of oceanic fronts. Anomalies of heat and fresh water fluxes in the presence of fronts have long been correlated with the presence of SST gradients that modify the interaction between atmosphere and ocean. Wind stress is intensified on the warm side, in particular through the direct modification of atmospheric lower layer stability [Chelton et al., 2004]. Temperature and humidity contrasts emphasize also the exchanges on the warm side. This was observed by Friehe et al. [1991] in the Frontal Air-Sea Interaction Experiment (FASINEX) in the Sargasso Sea. In their study, the warm side of the observed front $\left(2^{\circ} \mathrm{C} / 20 \mathrm{~km}\right)$ is clearly associated with a warming and moistening of the atmospheric boundary layer above it. This was also found for fairly weak meso-scale ocean structures at midlatitudes, as exemplified by Bourras et al. [2004], situations that might be rather similar to the summer conditions in the Irminger Sea. In addition, the deepening of the mixed layer from the cold side to the warm side of fronts (especially during weakly stratified periods) was described in earlier studies [Eriksen et al., 1991; Rudnick and Luyten, 1996], although this is not just related to air-sea fluxes, but can be associated with reduced stratification on the warm side, where isopycnals are lowered in the presence of eddying currents. There can also be the effect of secondary circulations around fronts, but which should not contribute much at the mesoscales considered here. Increased winds and buoyancy fluxes on the warm side will also imply more vertical stirring, and thus more mixing of the surface water with the deeper stratified ocean.

[42] Some of these effects are present in the ORCA025 eddy-permitting simulation that we examined with some important caveats: wind stress, air temperature and humidity been mostly imposed from ERA40 reanalyses are not 
influenced by the presence of the model surface fronts. The negative heat flux feedback induced by the meso-scale SST gradients causes a reduction of SST gradients and density ratios across fronts of a comparable magnitude to the observations in this region. The model also presented a negative salinity feedback due to a relaxation to climatology, an effect not present in the real ocean. Assuming that the heat flux feedback in this simulation at the meso-scale is relevant for the real ocean and taking seasonal mixed layer depths based on ARGO profiles, this term could induce the observed reduction in summer $\mathrm{T}$ gradients and density ratios at frontal scale over a time scale of 25-35 days. This is of course only partially true (as discussed by Small et al. [2008]), and a full examination of the effects of air-sea interaction would require a coupled ocean-atmospheric simulation at the meso-scale.

[43] The mixed layer depth modulation across fronts found in the model simulation could not be detected in XBT data collected by the Nuka Arctica. However, the XBT sections were not done with sufficiently high resolution until 20082009 in the Irminger Sea, and the database is too small to be able to extract a signal from a variable field, in particular due to short-term weather forcing of mixed layer variability, in particular in summer. This will need to be re-examined when the database of XBT sections will be larger.

[44] This summer reduction of near-front $T$ gradients results in observed average density ratios smaller than 1 (see Figure 7, when including only fronts identified in both $\mathrm{S}$ and $\mathrm{T}$ ). Thus the horizontal density gradient across the front is slightly reversed at the surface compared to subsurface. This would diminish in summer the surface jets associated with the fronts depicted in DRD, although the effect is not large due to shallow mixed layers. Indeed, when separating the salinity fronts of DRD according to surface density ratio, one finds weaker surface currents for small density ratios with a magnitude coherent with this effect. This could contribute to a reduction of surface eddy kinetic energy (SEKE) in summer in this region. However, the effect should remain small with summer reduction of surface currents with respect to subsurface on the order of $1 \mathrm{~cm} \mathrm{~s}^{-1}$ in the mapped altimetric currents we use. In the regions where the fronts are found (Irminger Current or central Irminger Sea, cf. Figure 5), current products indicate slightly larger meso-scale SEKE in spring than in summer [also Volkov, 2005; Stammer and Wunsch, 1999], a seasonality more likely induced by increased doming of the Irminger gyre and baroclinicity in spring.

[45] This meso-scale lowering of the density ratio that we attribute mostly to the heat flux negative feedback could compete with processes happening at smaller scales, typically less than $10 \mathrm{~km}$, resulting in different ways from mixing and dispersion preferentially reducing horizontal gradients in the density gradient direction [Ferrari and Young, 1997; Sundermeyer and Lelong, 2005]. Such processes have been held responsible for the observed dominance of nearly compensated surface fronts and near-1 density ratio in tropical and subtropical oceans on scales from $100 \mathrm{~m}$ to $10 \mathrm{~km}$ [Rudnick and Ferrari, 1999; Rudnick and Martin, 2002], at least during seasons when the mixed layer is deep enough. Whether and how this can influence the larger meso-scale contrasts at higher latitudes likely depends on the strength of these processes, relative to the large scale mechanisms of horizontal advection and air-sea fluxes, which should be investigated in very high resolution ocean-atmosphere coupled models.

\section{Conclusions}

[46] In the Irminger Sea, we found temperature and salinity meso-scale fronts in all seasons, albeit with a different pattern, to a large extent explained by the seasonal large scale temperature and salinity fields. The salinity jumps across the fronts are close (statistically) to their large $(200 \mathrm{~km})$ scale counterpart. However, the temperature jumps across the fronts present a seasonal cycle, and in summer time are smaller than the large scale temperature jumps. These observed frontal temperature jumps are also smaller than the frontal temperature jumps simulated using the back-trajectory method, which on the other hand reproduces well the salinity jumps. The difference is most pronounced for the summer season, and thus we focused on this season, which is also well sampled and during which three Ovide cruises took place (mostly in June). The Nuka Arctica summer fronts tend to be nearly compensated (or salinity dominated for the density). This is also observed in the Ovide cruises which indicate that horizontal density ratio near fronts in shallow summer time mixed layers (typically $30 \mathrm{~m}$ ) are lower than at subsurface, and that all subsurface fronts are associated with a nearby surface $\mathrm{S}$ front, but not always with a $\mathrm{T}$ front.

[47] The analysis of eddy-permitting ORCA025-G70 simulation suggested that atmospheric forcing at the mesoscale, directly through the heat and evaporation feedback on ocean SST gradients, or indirectly through modulation of vertical mixing, would result in a toning down of the temperature gradients near the meso-scale fronts compared to its salinity counterpart. This is also found in other ocean circulation models with similar forcing parameterizations [Shuckburgh et al., 2011]. This is however rather indirect evidence, as the observations on the air-sea fluxes do not resolve the meso-scales, as the model does not have an interactive atmospheric boundary layer, and as subsurface profiles are too few in this region to investigate the mixed layer structure and vertical mixing modulation associated with fronts in the stratified season. Further work should focus on implementing these observations, in particular through regular high resolution XBT sections associated with reliable meteorological observations as is done in other regions, but also on high resolution modeling of air-sea coupling at the meso- or sub-meso-scales.

[48] Acknowledgments. Data were collected on merchant vessels thanks to the cooperation of the companies EIMKIP and Royal Arctic Line and with the devoted help of the crews. Samples were analyzed by Magnus Danielsen (Hafrannsoknastofnun, Reykjavik, Iceland) and Lars Heilman and colleagues of the Department of Environment in Nuuk, Greenland. The Nuka Arctica data are collected as part of "Observatoire de Recherché en Environnement Sea Surface Salinity" in France. Ovide 2002, 2004 and 2006 cruises were done on IFREMER vessel R/V Thalassa, and the research was funded by various INSU grants (OVIDE, SURATLANT) and ANR REDHOTS. The altimeter products were produced by Ssalto/ Duacs and distributed by Aviso, with support from Centre National d'Etudes Spatiales. We also thank the French DRAKKAR project team for the ORCA-025-G70 simulation, as well as Stephen Okkonen and two anonymous reviewers for helpful suggestions. 


\section{References}

Bersch, M. (2002), North Atlantic Oscillation-induced changes of the upper layer circulation in the northern North Atlantic Ocean, J. Geophys. Res., 107(C10), 3156, doi:10.1029/2001JC000901.

Bourras, D., G. Reverdin, H. Giordani, and G. Caniaux (2004), Response of the atmospheric boundary layer to a mesoscale oceanic eddy in the northeast Atlantic, J. Geophys. Res., 109, D18114, doi:10.1029/ 2004JD004799.

Boyer, T. P., J. I. Antonov, H. E. Garcia, D. R. Johnson, R. A. Locarnini, A. V. Mishonov, M. T. Pitcher, O. K. Baranova, and I. V. Smolyar (2006), World Ocean Database 2005 [DVDs], NOAA Atlas NESDIS vol. 60, edited by S. Levitus, 190 pp., U.S. Govt. Print. Off., Washington, D. C.

Chelton, D. B., R. A. deSzoeke, M. G. Schlax, K. El Naggar, and N. Siwertz (1998), Geographical variability of the first baroclinic Rossby radius of deformation, J. Phys. Oceanogr., 28, 433-460, doi:10.1175/1520-0485 (1998)028<0433:GVOTFB >2.0.CO;2.

Chelton, D. B., M. G. Schlax, M. H. Freilich, and R. F. Milliff (2004), Satellite measurements reveal persistent small-scale features in ocean winds, Science, 303, 978-983, doi:10.1126/science.1091901.

Desprès, A., G. Reverdin, and F. D'Ovidio (2011), Mechanisms and spatial variability of meso scale frontogenesis in the northwestern subpolar gyre, Ocean Modell., doi:10.1016/j.ocemod.2010.12.005.

d'Ovidio, F., J. Isern-Fontanet, C. Lopez, E. Hernandez-Garcia, and G. L. Emilio (2009), Comparison between Eulerian diagnostics and finite-size Lyapunov exponents computed from altimetry in the Algerian basin, Deep Sea Res., Part I, 56, 15-31, doi:10.1016/j.dsr.2008.07.014.

Emery, W. J., W. G. Lee, and L. Magaard (1984), Geographic and seasonal distributions of Brunt-Väisälä frequency and Rossby radii in the North Pacific and North Atlantic, J. Phys. Oceanogr., 14, 294-317, doi:10.1175/1520-0485(1984)014<0294:GASDOB>2.0.CO;2.

Eriksen, C. C., R. A. Weller, D. L. Rudnick, R. T. Pollard, and L. A. Regier (1991), Ocean frontal variability in the frontal air-sea interaction experiment, J. Geophys. Res., 96(C5), 8569-8591, doi:10.1029/90JC02531.

Ferrari, R., and W. R. Young (1997), On the development of thermohaline correlations as a result of nonlinear diffusive parameterizations, J. Mar. Res., 55, 1069-1101, doi:10.1357/0022240973224094.

Flatau, M. K., L. Talley, and P. P. Niiler (2003), The North Atlantic Oscillation, surface current velocities, and SST changes in the subpolar North Atlantic, J. Phys. Oceanogr., 16, 2355-2369.

Fratantoni, D. M. (2001), North Atlantic surface circulation during the 1990's observed with satellite-tracked drifters, J. Geophys. Res., 106(C10), 22,067-22,093, doi:10.1029/2000JC000730.

Friehe, C. A., W. J. Shaw, D. P. Rogers, K. L. Davidson, W. G. Large, S. A. Stage, G. H. Crescenti, S. J. S. Khalsa, G. K. Greenhut, and F. Li (1991), Air-sea fluxes and surface layer turbulence around a sea surface temperature front, J. Geophys. Res., 96(C5), 8593-8609, doi:10.1029/ 90JC02062.

Gulev, S., B. Barnier, J. M. Molines, T. Penduff, and J. Chanut (2007), Impact of spatial resolution on simulated surface water mass transformations in the Atlantic, Ocean Modell., 19, 138-160, doi:10.1016/j.ocemod.2007.07.004.

Hatun, H., A. B. Sando, H. Hansen, and H. Valdimarsson (2005), Influence of the Atlantic subpolar gyre on the thermohaline circulation, Science, 309, 1841-1844, doi:10.1126/science.1114777.

Holliday, N. P., J. Waniek, R. Davidson, D. Wilson, L. Brown, R. Sanders, R. T. Pollard, and J. T. Allen (2006), Large scale physical controls on phytoplankton growth in the Irminger Sea. Part I: Hydrographic zones, mixing and stratification, J. Mar. Syst., 59, 201-218, doi:10.1016/j. jmarsys.2005.10.004

Lehahn, Y., F. d'Ovidio, M. Levy, and E. Heifetz (2007), Stirring of the northeast Atlantic spring bloom: A Lagrangian analysis based on multisatellite data, J. Geophys. Res., 112, C08005, doi:10.1029/2006JC003927.

Le Traon, P. Y., G. Dibarboure, and N. Ducet (2001), Use of a high resolution model to analyze the mapping capabilities of multiple-altimeter missions, J. Atmos. Oceanic Technol., 18, 1277-1288, doi:10.1175/ 1520-0426(2001)018<1277:UOAHRM >2.0.CO;2.
Lherminier, P., H. Mercier, C. Gourcuff, M. Alvarez, S. Bacon, and C. Kermabon (2007), Transports accross the 2002 Greenland-Portugal Ovide section and comparison with 1997, J. Geophys. Res., 112, C07003, doi:10.1029/2006JC003716.

Lique, C., A. M. Tréguier, M. Scheinert, and T. Penduff (2009), A modelbased study of ice and freshwater transport variability along both sides of Greenland, Clim. Dyn., 33, 685-705, doi:10.1007/s00382-008-0510-7.

Liu, W. T., K. B. Katsaros, and J. A. Businger (1979), Bulk parameterizations of air-sea exchanges of heat and water vapor including the molecular constraints at the interface, J. Atmos. Sci., 36, 1722-1735, doi:10.1175/1520-0469(1979)036<1722:BPOASE > 2.0.CO;2.

Molines, J. M., B. Barnier, T. Penduff, L. Brodeau, A. M. Tréguier, S. Theetten, and G. Madec (2006), Definition of the interannual experiment ORCA025-G70, 1958-2004, LEGI Rep. LEGI-DRA-2-11-2006, Lab. Des Ecoulements Geophys. et Ind., Grenoble, France. [Available at http://www.drakkar-ocean.eu/.]

Pollard, R. T., J. F. Read, and N. P. Holliday (2004), Water masses and circulation pathways through the Iceland Basin during Vivaldi 1996 J. Geophys. Res., 109, C04004, doi:10.1029/2003JC002067.

Reverdin, G., F. Durand, J. Mortensen, F. Schott, H. Valdimarsson, and W. Zenk (2002), Recent changes in the surface salinity of the North Atlantic subpolar gyre, J. Geophys. Res., 107(C12), 8010, doi:10.1029/ 2001JC001010.

Reverdin, G., P. P. Niiler, and H. Valdimarsson (2003), North Atlantic Ocean surface currents, J. Geophys. Res., 108(C1), 3002, doi:10.1029/ 2001JC001020.

Reynolds, R. W., and T. M. Smith (1994), Improved global sea surface temperature analyses using optimum interpolation, J. Clim., 7, 929-948, doi:10.1175/1520-0442(1994)007<0929:IGSSTA>2.0.CO;2.

Rio, M. H., and F. Hernandez (2004), A mean dynamic topography computed over the world ocean from altimetry, in situ measurements, and a geoid model, J. Geophys. Res., 109, C12032, doi:10.1029/ 2003JC002226.

Rudnick, D. L., and R. Ferrari (1999), Compensation of horizontal temperature and salinity gradients in the ocean mixed layer, Science, 283, 526-529, doi:10.1126/science.283.5401.526.

Rudnick, D. L., and J. R. Luyten (1996), Intensive surveys of the Azores front: 1. Tracers and dynamics, J. Geophys. Res., 101(C1), 923-939, doi:10.1029/95JC02867.

Rudnick, D. L., and J. P. Martin (2002), On the horizontal density ratio in the upper ocean, Dyn. Atmos. Oceans, 36, 3-21, doi:10.1016/S03770265(02)00022-2.

Shuckburgh, E., G. Mazé, D. Ferreira, J. Marshall, H. Jones, and C. Hill (2011), Mixed layer lateral eddy fluxes mediated by air-sea interaction, J. Phys. Oceanogr., 41, 130-144, doi:10.1175/2010JPO4429.1.

Small, R. J., S. P. deSzoecke, S. P. Xie, L. O’Neill, H. Seo, Q. Song, P. Cornillon, M. Spall, and S. Minobe (2008), Air-sea interaction over ocean fronts and eddies, Dyn. Atmos. Oceans, 45, 274-319, doi:10.1016/ j.dynatmoce.2008.01.001.

Stammer, D., and C. Wunsch (1999), Temporal changes in eddy energy of the oceans, Deep-Sea Res. Part II, $46 \mathrm{ka}, 77-108$.

Sundermeyer, M. A., and M. P. Lelong (2005), Numerical simulations of lateral dispersion by the relaxation of diapycnal mixing events, J. Phys. Oceanogr., 35, 2368-2386, doi:10.1175/JPO2834.1.

Thierry, V., E. de Boisseson, and H. Mercier (2008), Interannual variability of the Subpolar Mode Water properties over the Reykjanes Ridge during 1990-2006, J. Geophys. Res., 113, C04016, doi:10.1029/2007JC004443.

Volkov, D. L. (2005), Interannual variability of the altimetry-derived eddy field and surface circulation in the extratropical North Atlantic Ocean in 1993-2001, J. Phys. Oceanogr., 35, 405-426, doi:10.1175/JPO2683.1.

Xie, S. P. (2004), Satellite observation of cool ocean-atmosphere interaction, Bull. Am. Meteorol. Soc., 85, 195-208, doi:10.1175/BAMS-85-2-195.

A. Desprès, F. d'Ovidio, and G. Reverdin, LOCEAN, Institut PierreSimon Laplace, Université Pierre et Marie Curie, 4 place Jussieu, F-75005 Paris, France. (Gilles.reverdin@locean-ipsl.upmc.fr) 